(2) Open Access Full Text Article

REVIEW

\title{
Systematic review of school and community- based fruit and vegetable interventions for minority children
}

This article was published in the following Dove Press journal:

Pediatric Health, Medicine and Therapeutics

26 September 2014

Number of times this article has been viewed

\author{
Sarah E Rush \\ Adam P Knowlden \\ Department of Health Science, \\ The University of Alabama, \\ Tuscaloosa AL, USA
}

Correspondence: Sarah E Rush Department of Health Science, The University of Alabama, PO Box 87031 I, Tuscaloosa, AL 35487-03 I I, USA

Tel + I 2053489717

Email rush005@crimson.ua.edu
Background: Schools and communities provide effective environments to change health behaviors in children and adolescents, particularly among minority populations. The purpose of this investigation was to systematically analyze community and school-based interventions aimed at increasing fruit and vegetable intake (FVI) among minority children.

Methods: In collecting materials for this review, a search of CINAHL, MEDLINE, ERIC, Academic Search Premier, and Cochrane Central Register of Controlled Trials was conducted for articles spanning January 2003 to November 2013. The data extraction covered three phases, resulting in a total of eleven interventions that met the specified inclusion criteria.

Results: Among the studies identified, ten interventions produced significant outcomes on observed variables. The majority of the programs incorporated multicomponent approaches aimed at increasing FVI and antecedents of FVI behavior. Eight of the interventions applied social cognitive theory, one reported use of other theories, and two did not apply theory. None of the interventions reviewed employed process evaluation.

Conclusion: While both school and community-based interventions utilized over the past decade have separately shown significant impacts on changing dietary behaviors in children, community members and organizations can serve as supplementary approaches to partner with schools and design even more successful interventions based on these combined resources. School and community-based interventions have had a great deal of success in impacting self-efficacy levels as well as actual eating behaviors in children; however, the school and community-based interventions reviewed both noted lack of resources as a limitation. Therefore, combining these resources has the potential to help create more high-quality studies from which to draw evidence-based conclusions on the most effective means of impacting health behaviors among minority children in the school and community settings.

Keywords: children, fruit and vegetable, interventions, minority, social cognitive theory, goal setting

\section{Introduction}

Obesity prevalence rates among school-aged children and adolescents have reached alarming levels during the last three decades, both nationally and internationally, ${ }^{1,2}$ increasing almost four-fold from approximately 5\% to $19 \%$ among children aged 6-11 years of age in the USA.,3 The burden of obesity is disproportionately experienced by minority groups and low-income families in developed countries. ${ }^{4,5}$ Data from the 2009-2010 National Health and Nutrition Examination Survey ${ }^{6}$ showed significant differences by race/ethnicity, with Mexican Americans being significantly more likely to have a high weight-for-recumbent length than non-Hispanic whites. ${ }^{4}$ This same survey revealed a significant difference in the prevalence of obesity among 
minority children, including non-Hispanic black, Hispanic, and Mexican-Americans, when compared with non-Hispanic whites. Several studies noted that while the prevalence of overweight in US children has increased by $45 \%$ over the past two decades, ${ }^{7-9}$ the increase for African-American girls was $120 \% .^{10}$

Healthful eating is well documented as a behavior targeted to reduce disease risk in both children and adults. ${ }^{11}$ Increased consumption of fruit and vegetables has been associated with decreased incidence of and mortality from chronic disease, including cardiovascular disease, stroke, hypertension, diabetes, obesity, and certain cancers. ${ }^{12}$ Adopting a healthy diet, such as increased fruit and vegetable intake (FVI), should begin early in life. ${ }^{13,14}$ On the contrary, inadequate FVI has been deemed a significant risk factor for childhood obesity, and may be associated with a higher risk of development of many chronic diseases in adulthood, such as obesity, cardiovascular disease, diabetes, and cancer, ${ }^{15}$ creating a strong need to encourage children to cultivate preferences for these particular foods. ${ }^{12,16-21}$ Although intake of lowcalorie, nutrient-dense fruit and vegetables is associated with increased long-term health and a reduced risk of obesity, the current food environment, particularly in lower socioeconomic communities, is not one that encourages children to develop preferences for healthy foods. ${ }^{20-22}$

Children in the USA are consuming far less that the recommended amounts of fruit and vegetables per day. ${ }^{23}$ Currently, less than an estimated $10 \%$ of youth nationwide consume four to five servings of fruit and vegetables each day. ${ }^{24}$ Among minority children, findings suggest this group has less frequent consumption of fruit and vegetables than the majority of their non-Hispanic peers. ${ }^{25}$ On average, nonHispanic blacks and Mexican-American children consume 1.55 servings of fruit and vegetables daily compared with their non-Hispanic white peers who consume an average of 3.6 servings of fruit and vegetables daily. ${ }^{25,26}$ Another study reported that children and adolescents from lower socioeconomic groups consume fewer fruit and vegetable servings than those from higher socioeconomic groups. ${ }^{27}$ Thus, interventions targeting FVI in minority children are imperative and have the potential for significant impact on overall quality of life, including obesity-related conditions and decreased risk of morbidity and mortality in adulthood. ${ }^{28}$

While minority children may lack accessibility to fruit and vegetables in the home, which may affect overall fruit and vegetable consumption, these foods are often available to children who partake in the US Department of Agriculture's National School Lunch and Breakfast programs. ${ }^{29,30}$
However, even with this accessibility, many children are not familiar with these foods, have not developed a preference for them, and will not eat them when provided with a choice to do so. ${ }^{31}$ While children are born with a preference for energy-dense foods that are sweet and salty, previous studies have shown that when given the opportunity, children become more accepting of new foods as they grow older and can develop a preference for many foods that they initially refuse. $^{32-36}$

Schools have been identified as central environments in which to beneficially impact children's lives, including health behaviors. ${ }^{37}$ Schools provide a reassuring environment where educators can serve as role models and young children can develop preferences for healthy foods at a young age, before poor dietary behaviors have been fully developed. ${ }^{38}$ However, changing behaviors in children is not as simple as providing them with information; successful programs must combine education with feedback, role modeling, and exposure. ${ }^{39}$ Previous studies have examined multicomponent school-based programs that have been designed and tested to encourage and increase FVI in children, but these interventions have produced unclear results and often require more resources than are available to the schools. ${ }^{40-42}$

Communities have the potential to partner with schools and may play a crucial role in the development of successful interventions aimed at increasing FVI in children and adolescents by including opportunities for cooking classes, recipe preparation, garden engagement, and food cooperatives, as well as providing resources not available in schools. ${ }^{21,43,44}$ Given these results, public health interventions for reducing overweight and obesity prevalence rates among minority populations are critical. ${ }^{12,16-21}$ Therefore, the purpose of this investigation was to systematically review and synthesize community and school-based interventions aimed at increasing FVI among minority children.

\section{Materials and methods}

Inclusion criteria for this review were: i) prevention studies ii) of any quantitative design iii) published in the English language iv) conducted both nationally and internationally v) between 2003 and 2013 vi) that targeted both antecedents to FVI and/or actual FVI, vii) were multicomponent interventions, viii) targeting school-aged children ix) in the community or school environment. Exclusion criteria included interventions i) that were ongoing, ii) conducted exclusively in the home environment, iii) did not prioritize minority (specifically Native American, Hispanic and African-American) children, iv) and were not indexed 
in one of the following databases: Cumulative Index to Nursing and Allied Health (CINAHL), Medline, Education Resources Information Center (ERIC), Academic Search Premier, and Cochrane Central Register of Controlled Trials (CENTRAL).

The data extraction process consisted of three phases (see Figure 1). Phase 1 incorporated Boolean search logic to obtain the first round of articles from the CINAHL $(n=3)$, ERIC ( $n=5)$, MEDLINE ( $n=8)$, Academic Search Premier $(n=18)$, and CENTRAL $(n=2)$ databases. Phase 2 further distilled the identified articles, by removing duplicates $(n=2)$, studies that did not employ interventions $(n=10)$, were irrelevant to the research question $(n=5)$, and review articles $(n=1)$. During phase 3 , the refined list of articles $(n=18)$ was reviewed independently by two researchers to ensure consistent adherence to inclusion/exclusion criteria.
Results of the independent analyses confirmed that four of the studies were ongoing and three included a home-based component. Therefore, these articles were not studied in this review. Lastly, descendent search of all references cited from the articles identified in phase 3 was conducted to locate publications that did not populate during the primary search process. No additional studies were identified with this process.

\section{Results}

The completed data extraction process resulted in eleven studies that satisfied the inclusion and exclusion criteria (see Figure 1). Table 1 summarizes the elements of each study's research design, including target population, age of participants enrolled, theoretical framework employed, intervention groups, intervention duration, evaluation

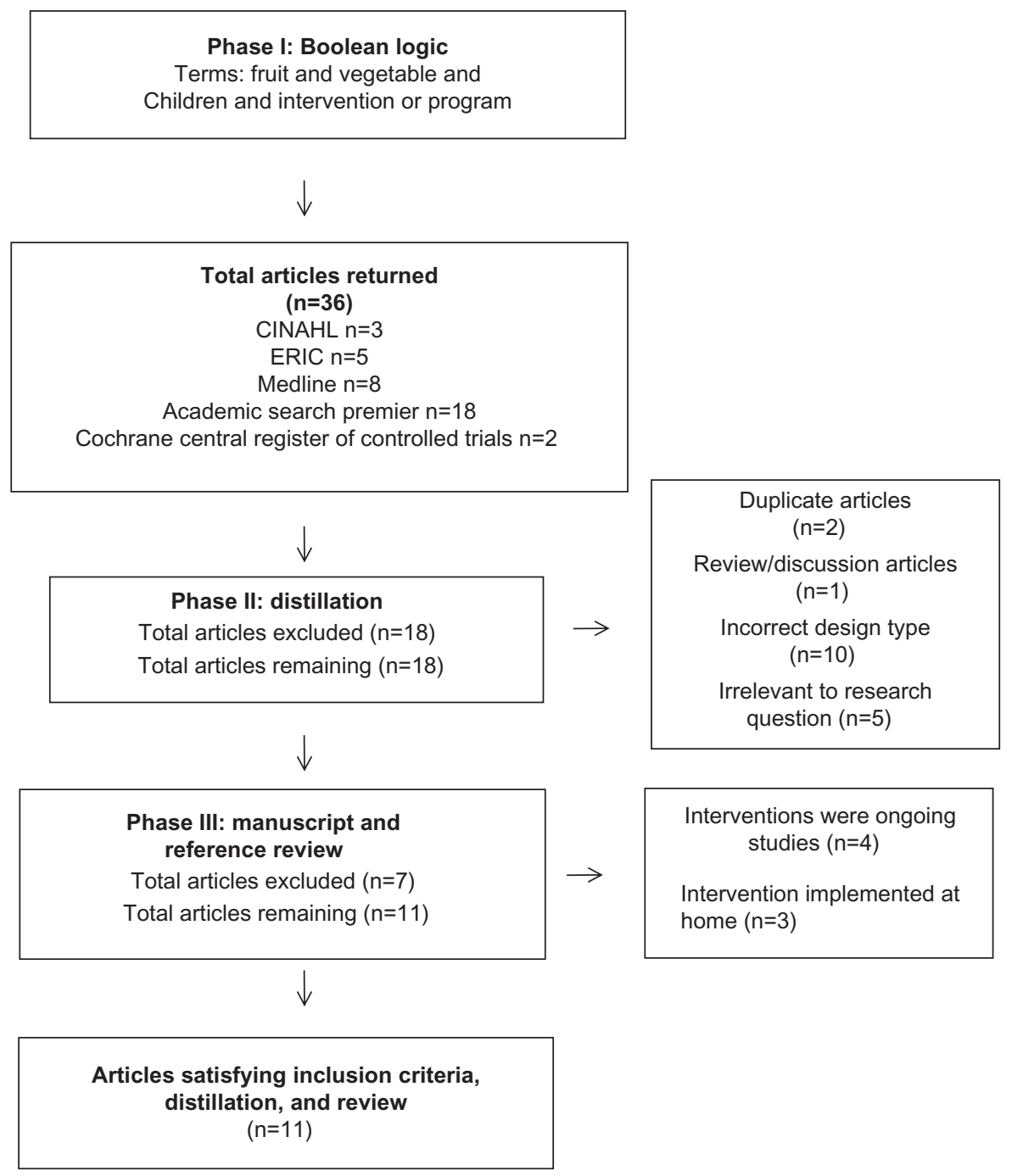

Figure I Flow chart depicting the three phase data extraction process.

Abbreviations: CINAHL, Cumulative Index to Nursing and Allied Health Literature; ERIC, Education Resources Information Center. 
Table I Summary of school and community-based interventions targeting fruit and vegetable intake in minority children ( $\mathrm{n}=12$ )

\begin{tabular}{|c|c|c|}
\hline Design & $\begin{array}{l}\text { Theoretical } \\
\text { framework }\end{array}$ & Intervention groups \\
\hline - RCT & $\begin{array}{l}\text { - Social cognitive } \\
\text { theory }{ }^{45}\end{array}$ & $\begin{array}{l}\text { - } 16 \text { groups pair-matched then randomly } \\
\text { assigned to treatment or control } \\
\text { - Treated: children }(\mathrm{n}=269) \text { from } \\
7 \text { schools, } 44.6 \% \text { fourth graders, } \\
51.4 \% \text { fifth graders } \\
\text { - Control: children ( } \mathrm{n}=29 \mathrm{I}) \text { from } \\
7 \text { schools, } 55.4 \% \text { fourth graders, } \\
48.6 \% \text { fifth graders }\end{array}$ \\
\hline - Cluster RCT & $\begin{array}{l}\text { - Social cognitive } \\
\text { theory }^{45}\end{array}$ & $\begin{array}{l}\text { - } 26 \text { schools randomly assigned to } \\
\text { treatment or control } \\
\text { - Treatment: children }(n=67 \text { I) from } \\
\text { I3 schools } \\
\text { - Control: children }(n=907) \text { from } \\
\text { I3 schools }\end{array}$ \\
\hline - Quasi-experimental pilot study & $\begin{array}{l}\text { - Social cognitive } \\
\text { theory }^{45}\end{array}$ & $\begin{array}{l}\text { - Treatment: children }(\mathrm{n}=34) \text { within } \\
\text { Los Angeles school district enrolled } \\
\text { in after school program (school was } \\
\text { in close geographic distance to } \\
\text { community garden), 61.4\% female } \\
\text { - Control: students ( } \mathrm{n}=70 \text { ) were not } \\
\text { enrolled in after school program and } \\
\text { were invited to participate, abbreviated } \\
\text { intervention offered to control } \\
\text { participants at completion of program, } \\
41.4 \% \text { female }\end{array}$ \\
\hline
\end{tabular}

- Posttest only control group design

- Evaluation of baseline data from treatment $\mathrm{I}-4$ and control groups confirmed groups did not differ significantly on main outcomes at early stage of intervention

- RCT

\author{
- Social cognitive \\ theory ${ }^{45}$ \\ - Treatment I-4: children $(n=176)$ \\ received at least 2 components of
intervention
- Control: children $(n=70)$ not
intervention
- Control: children $(n=70)$ not exposed to any components

- Social cognitive theory ${ }^{45}$ exposed to any components same number and frequency of

\begin{tabular}{|c|c|}
\hline \# & $\begin{array}{l}\text { Program/target population/age of } \\
\text { children }\end{array}$ \\
\hline I. & $\begin{array}{l}\text { - "Smart Bodies" } 44 \\
\text { - Tuuri et al } \\
\text { - Native American children (low-income, } \\
\text { urban, public elementary schools in East } \\
\text { Baton Rouge Parish, LA, USA) } \\
\text { - Majority were African American (82\%) } \\
\text { - } 68.2 \%-98.5 \% \text { of students enrolled in } \\
\text { - National School Lunch Program } \\
\text { - Fourth and fifth grade }\end{array}$ \\
\hline 2. & $\begin{array}{l}\text { - "Squire's Quest!" } 46 \\
\text { - Cullen et al } \\
\text { - Native American children (from Houston, } \\
\text { TX, USA, area elementary schools) } \\
\text { - Majority African-American ( } 41.6 \% \text { ) or } \\
\text { Hispanic ( } 29.8 \% \text { ) and low-income } \\
\text { - } 65.7 \% \text { of students in school district } \\
\text { eligible for free or reduced price lunches } \\
\text { - Fourth grade }\end{array}$ \\
\hline 3. & $\begin{array}{l}\text { - "LA Sprouts" } 48 \\
\text { - Gatto et al } \\
\text { - Predominantly Latino children (from Los } \\
\text { Angeles, CA, USA, area elementary } \\
\text { schools) } \\
\text { - } 59.8 \% \text { were overweight or obese } \\
\text { (BMI } \geq 85 \text { th percentile) } \\
\text { - } 94 \% \text { of student body eligible for free or } \\
\text { reduced-price school meals } \\
\text { - Fourth and fifth grade (age 9-II years) }\end{array}$ \\
\hline
\end{tabular}

- Majority Hispanic (59\%) and lowincome (70\%)

- $70 \%$ or more of students at school eligible for free or reduced price lunches

- Sixth and seventh grade

5. Memphis GEMS ${ }^{50}$

- Klesges et al

- African-American pre-adolescent females (recruited from community in Memphis, TN, USA)

- 8-10 years old

- BMI z-score between 25-35

- Native American children (from five ethnically diverse middle schools in Austin, TX, USA)

BMl 25 -35
- Treatment I and 2: both groups had sessions $(n=303)$

- Treatment I: girls ( $n=153)$ received intervention focused on obesity prevention

- Treatment 2: girls $(n=150)$ received intervention focused on building social awareness and community responsibility 


\section{Duration/intervention activities \\ - 12 week program measured at baseline and post-intervention \\ - Interactive school assemblies \\ - Daily classroom activity using teacher- directed materials \\ - Classroom curriculum (videos, books, games, and lessons) emphasized FV consumption}

- 10 session (10-week) program measured baseline and post-intervention

- Interactive multimedia game

- 4 days of dietary assessment during twoweek baseline prior to program and 4 days of post dietary assessment two weeks after program

- Each child completed 2 sessions of “Squires Quest!" per week for 5 weeks

- I2-week program measured baseline and post-intervention (I week before and I week after)

- 90-minute weekly sessions included: 45-minute cooking and nutritional education lesson, focused on culturally relevant $\mathrm{FV}$

45-minute interactive gardening component taught by master gardener

- Local farmers market visits 4 times in 12 weeks

- 4 month program measured postintervention

- In-class lessons

- Cafeteria component (farm-to-school)

- Farmer visits component

- Taste-testing component

- After-school component

- Field trip to farms

- 2 year program with baseline, I year follow-up and 2 year follow-up visits

- Weekly meetings for 14 weeks followed by monthly meetings for 20 months (34 sessions in 2 years)

- Each session lasted 90-minutes

- 2nd year interventions transitioned into monthly field trips within community

\section{Evaluation measures Intervention effects}

- FV survey:

FV preferences

Social cognitive theory measures related to FV consumption (selfefficacy, outcome expectations, and social norms)

Knowledge of nutrition-related information

- FIRSSt $^{47}$

- FV, and fruit juice preferences

- Self-efficacy

- Fruit-juice and vegetable recipe preparation goals

- BMI z-score

- Body fat percentage

- Attitudes, preferences, perceptions and self-efficacy to eat and cook FV

- Acculturation, Habits, and Interests Multicultural Scale for Adolescents

- Adaption of the Motivation for Healthy Behaving Measure from the Treatment and SelfRegulation Questionnaire

- School Engagement Questionnaire

- Student SHK Questionnaire: Motivation for eating FV, preferences for FV and unhealthy foods, self-efficacy for eating FV, and cognitive knowledge

- F\&V Food Frequency Questionnaire

- BMI z-score at 2-years post intervention

- Waist circumference

- Accelerometer

- Triceps skinfold thickness

- Bioelectrical impedance

- Sexual maturation

- 24-hour dietary recall on 3 nonconsecutive days
- Increased nutrition knowledge for children in treatment I $(P<0.00 \mathrm{I})$

- Increased self-efficacy to consume fruit, drink juice, eat fruit instead of a favorite dessert/cookies/candy and consume recommended number of FV each day $(P<0.001)$

- Decreased preferences in fourth grade students for certain healthy foods $(P<0.001)$, while fifth graders preferences for the same items did not change

- Increase in fruit, fruit juice, and vegetable servings was achieved at post assessment $(P<0.00 \mathrm{I})$

- Girls achieved more recipe preparation than boys

- Hispanic children achieved higher levels of fruit-juice and vegetable recipe preparation

- Sex (female) $(P<0.05)$, higher baseline vegetable preference $(P<0.00 \mathrm{I})$, and having a mother with a college education or more $(P<0.05)$ were significant predictors of post-vegetable consumption

- Improvements preferences for vegetables overall $(P=0.06)$, but not fruits

- 2.l-point (16\%) increase in preference for vegetables overall among overweight and obese subgroups $(P=0.009)$

- 3.9-point increase in preference for vegetables overall among female participants $(P<0.05)$

- Treatment I was $54 \%$ more likely to report that "vegetables from the garden taste better than vegetables from the store" $(P<0.05)$

- Treatment I showed a greater change in perceptions that cooking is easy $(P<0.00 \mathrm{I})$ and gardening is easy $(P<0.05)$

- Treatment I participants showed increase in self-efficacy from preintervention to post-intervention

- Reductions in weight among treatment I participants were associated with increased preference for vegetables $(P=0.09)$ and fiber from fruit $(P=0.08)$

- Higher scores on knowledge measure at posttest $(P=0.02)$ and marginally lower on preference for unhealthy foods $(P=0.07)$

- Students exposed to more than 2 components of program scored significantly higher on FVI, self-efficacy and knowledge $(P<0.05)$ and significantly lower on preference for unhealthy foods scale $(P<0.01)$

- Farmers visit intervention had largest treatment effect on participants FVI (0.52 servings/day increase)

- FVI increased by 0.352 servings for every additional component of intervention exposure $(P<0.0 \mathrm{I})$

- Increase in mean daily vegetable intake among girls in treatment I compared with treatment $2(P=0.03)$

- No differences in BMI z-score or any other anthropometric measures between treatments I and 2 at I-year and 2-year follow up

- All girls reported increases in mean intake of sweetened beverages, but treatment I group had 0.19 fewer servings per day than treatment 2 at 2-year visit $(P=0.08)$

- Treatment I group reported increased water consumption from baseline and at 2 years had 0.21 more servings per day than treatment $2(P=0.02)$

- PA did not differ significantly between the 2 groups at either I-year or 2-year follow-up visit 
Table I (Continued)

\begin{tabular}{|c|c|c|c|c|}
\hline$\#$ & $\begin{array}{l}\text { Program/target population/age of } \\
\text { children }\end{array}$ & Design & $\begin{array}{l}\text { Theoretical } \\
\text { framework }\end{array}$ & Intervention groups \\
\hline 6. & $\begin{array}{l}\text { - Somerville et al study }{ }^{51} \\
\text { - Native American children (active } \\
\text { participants in Boys and Girls Club } \\
\text { gardening program in Pomona, CA, USA) } \\
\text { - Majority were Hispanic ( } 83 \%) \\
\text { - } 6-12 \text { years old }\end{array}$ & $\begin{array}{l}\text { - One group pretest - posttest } \\
\text { design }\end{array}$ & $\begin{array}{l}\text { - Social cognitive } \\
\text { theory }^{45}\end{array}$ & $\begin{array}{l}\text { - Treatment: children }(n=40) \text { received } \\
\text { intervention }\end{array}$ \\
\hline 7. & $\begin{array}{l}\text { - "Every Day, Lots of Ways" } 52 \\
\text { - Blom-Hoffman et al } \\
\text { - African-American students attending } \\
\text { an under-resourced urban school (in } \\
\text { northeastern USA) } \\
\text { - } 95 \% \text { of students at school received free } \\
\text { breakfast and lunch } \\
\text { - Kindergarten and first grade }\end{array}$ & - $\mathrm{RCT}$ & $\begin{array}{l}\text { - Social learning } \\
\text { theory }^{45}\end{array}$ & $\begin{array}{l}\text { - Treatment I: students ( } \mathrm{n}=9 \mathrm{I}) \text {, from } \\
\text { three randomly assigned classrooms } \\
\text { - WLC: students from three randomly } \\
\text { assigned kindergarten and first grade } \\
\text { classrooms received entire program } \\
\text { after posttest was completed with } \\
\text { treatment I }\end{array}$ \\
\hline 8. & $\begin{array}{l}\text { - Students and Parents Actively Involved } \\
\text { in Being } \text { Fit }^{53} \\
\text { - Engels et al } \\
\text { - African-American students and their } \\
\text { parents/guardians at an urban middle } \\
\text { school in after-school intervention, USA } \\
\text { - Children ages II.I } \pm I .3 \text { years; adults } \\
\text { ages } 40.6 \pm 7.7 \text { years }\end{array}$ & $\begin{array}{l}\text { - One group pretest - posttest } \\
\text { design }\end{array}$ & $\begin{array}{l}\text { - No reported } \\
\text { theoretical } \\
\text { framework }\end{array}$ & $\begin{array}{l}\text { - Treatment: children }(n=56) \text { and } \\
\text { parents/guardians }(n=25) \text { received } \\
\text { entire intervention }\end{array}$ \\
\hline 9. & $\begin{array}{l}\text { - Go Girls } \\
\text { - Resnicow et al } \\
\text { - African-American adolescent females } \\
\text { - } 10 \text { predominantly middle socioeconomic } \\
\text { status churches in USA } \\
\text { - I2-I5 years old (mean age } 14 \text { years) } \\
\text { - BMI z-score above 90th percentile for } \\
\text { age and sex } \\
\text { - Parents invited to attend every other } \\
\text { session }\end{array}$ & - $\mathrm{RCT}$ & $\begin{array}{l}\text { - Social cognitive } \\
\text { theory }^{45}\end{array}$ & $\begin{array}{l}\text { - Treatment I: High intensity culturally } \\
\text { tailored behavioral group intervention } \\
\text { ( } n=5 \text { churches) } \\
\text { - Treatment 2: Moderate intensity } \\
\text { culturally tailored behavioral group } \\
\text { intervention ( } n=5 \text { churches), served } \\
\text { as comparison group } \\
\text { - I47 girls completed baseline, } \\
\text { I23 completed 6-month follow-up, } \\
\text { I07 completed I-year follow-up }\end{array}$ \\
\hline 10 & $\begin{array}{l}\text { - One Body, One Life } 55 \\
\text { - Towey et al } \\
\text { - Children and adults from local schools } \\
\text { and community groups (in Coventry, UK) } \\
\text { - Ethnically diverse families from deprived } \\
\text { areas in Coventry ( } 77 \% \text { from two most } \\
\text { deprived quintiles) } \\
\text { - One or more member of the family is } \\
\text { underweight, overweight, or obese } \\
\text { - Children } 7-16 \text { years, must be } \\
\text { accompanied by adult }\end{array}$ & $\begin{array}{l}\text { - One group pretest - posttest } \\
\text { design }\end{array}$ & $\begin{array}{l}\text { - No reported } \\
\text { theoretical } \\
\text { framework }\end{array}$ & $\begin{array}{l}\text { - Treatment I: children }(n=221) \text { and } \\
\text { adults/caregivers }(n=137) \text { received } \\
\text { entire intervention }\end{array}$ \\
\hline
\end{tabular}




\section{Duration/intervention activities}

- 4 month program measured at baseline and post-intervention

- Weekly one-hour session for 13 weeks

- Snack preparation activities

- Blind taste testing

- Apple stamping

- Produce Pictionary

- Fruit and Veggie Bingo

- Snack preparation for staff and family members

- 5-week program measured at baseline, post-intervention, and I-month follow-up

- 10 lessons (2 per week) addressing 5-ADay goal

- Classroom-based knowledge change component

- Lunchtime-based behavioral change component

- Home component

- I2-week program measured at baseline and post-intervention

- 4 days each week, 60-75 minutes per session

- Supervised dance

- Sport games

- Fitness activities

- Step pedometers

- Nutrition learning activities

- 6 month program measured at baseline, 6-month post-intervention, and I-year post-intervention (only anthropometric measures, BP, and shuttle test)

- 20-26 sessions for treatment 1, 6 sessions for treatment 2

- Experiential behavioral activity

- Approximately 30 minutes of PA

- Preparation and tasting of healthy foods

- Treatment I received 4-6 telephone counseling calls

- 10-12 week program measured at baseline and post-intervention

- Weekly 90-minute sessions

- Healthy eating workshop (45 minutes)

- PA workshop (45 minutes)

\section{Evaluation measures Intervention effects}

- BMI z-score

- Daily FV intake

- Snack preferences

- Knowledge

- Vegetable Eating Behaviors based on visual estimates of plate waste, rated according to Comstock Scale ${ }^{2}$

- Treatment Integrity Checks

- Treatment Acceptability Measures

- CIRP $^{3}$

- BMI z-score

- Daily FVI with brief food frequency research questions

- Step counts

- Body fat

- Resting heart rate and blood pressure

- Fitness run/walk test
- BMI z-score

- Body fat percentage

- Serum insulin

- Glucose

- Lipids

- Cardiovascular fitness

- Overall perception of program and intervention elements
- Waist and hip circumference

- Increased fruit and vegetable servings consumed daily $(P<0.05)$

- Self-reported scores for daily fruit servings increased from $2.23 \pm 4.18$ to $4.13 \pm 2.16$

- Self-reported scores for daily vegetable servings increased from $2.17 \pm 1.82$ to $3.07 \pm 1.87$

- Upward trends shown in FV snack preference

- Average number of FV servings increased, average number of chip servings decreased

- Increased nutrition knowledge for treatment I at posttest compared with WLC $(P<0.00 \mathrm{I})$

- No differences between knowledge scores for treatment I at posttest and I-month follow-up

- Significant increase in knowledge scores for WLC at posttest relative to pretest scores $(P<0.001)$

- No significant change in treatment I vegetable consumption from pre- to post-intervention and post-intervention rates were similar to those of WLC

- Significant decreases in BMI z scores $(P=0.002)$, body fat percentage $(P=0.004)$, resting diastolic blood pressure $(P=0.03 \mathrm{I})$, and walk/run time $(P=0.007)$ in parents/guardians

- Significant decreases in resting systolic blood pressure $(P<0.00 \mathrm{I})$ and resting diastolic blood pressure $(P<0.00 \mathrm{I})$ in children

- Increase in fruit consumption in parents/guardians and children

- Improvements in fruit juice, salad, and nonfried potato consumption in children

- Children gained more diet-related benefits while parents/ guardians gained more fitness-related benefits

- No significant difference in BMI z-score at 6-month follow-up between treatments I and 2

- No significant group differences in secondary outcomes

- Girls in treatment I who attended more than three-quarters of the sessions had significantly lower BMI z-score (2.2 units difference, $P=0.0 \mathrm{I}$ ), weight ( 10.1 pounds difference, $P=0.07$ ) and body fat percentage ( $2.5 \%$ difference, $P=0.01$ ) compared with girls in same group who attended fewer sessions

- Waist and hip circumferences of girls in treatment I who attended more than three quarters of the sessions were also significantly lower than those who attended less frequently $(P<0.05)$

- BMI z-score

- Body fat percentage

- Total body water

- Visceral fat

- Healthy eating knowledge quiz

- Eating behaviors - 24 hour recall

- PA - previous week recall
- Number of participants consuming 5 or more FV a day increased from $21 \%$ to $33 \%$, with an increase of 0.57 portions $(P<0.00 \mathrm{I})$ for children and 0.76 portions $(P<0.00 \mathrm{I})$ for adults

- Significant reduction in amount of chips, crisps, sweets, and fizzy drinks consumed per day for children of 0.32 portions $(P=0.002)$ and 0.34 portions for adults $(P=0.01)$

- Decrease in fast food consumption, although not significant for children $(P=0.08)$, but was significant for parents $(P<0.00 \mathrm{I})$

- Significant changes in knowledge, activity, and FV portions per day were found in both children and adults $(P<0.00 \mathrm{I})$ 
Table I (Continued)

\begin{tabular}{|c|c|c|c|c|}
\hline \# & $\begin{array}{l}\text { Program/target population/age of } \\
\text { children }\end{array}$ & Design & $\begin{array}{l}\text { Theoretical } \\
\text { framework }\end{array}$ & Intervention groups \\
\hline $\mathrm{II}$ & $\begin{array}{l}\text { - Aventuras Para Niños }{ }^{56} \\
\text { - Crespo et al } \\
\text { - Latino parents and their children (in San } \\
\text { Diego, CA, USA) } \\
\text { - Families had no major health problems } \\
\text { and lived within school attendance } \\
\text { boundaries } \\
\text { - Kindergarten through second grade }\end{array}$ & $\begin{array}{l}\text { Cluster RCT (I } 3 \text { schools } \\
\text { randomized to I of } 4 \text { conditions, } \\
n=808)\end{array}$ & $\begin{array}{l}\text { - Health belief } \\
\text { model, }{ }^{57} \text { social } \\
\text { cognitive } \\
\text { theory }^{45}\end{array}$ & $\begin{array}{l}\text { - Treatment I: } 3 \text { schools ( } n=198 \text { ) } \\
\text { received individual/family level } \\
\text { (family-only) } \\
\text { - Treatment } 2 \text { : } 3 \text { schools ( } n=2 / 8) \\
\text { received school/community level } \\
\text { (community-only) } \\
\text { - Treatment } 3: 3 \text { schools ( } n=165 \text { ) } \\
\text { received combined (family and } \\
\text { community) } \\
\text { - Control: } 4 \text { schools ( } n=227 \text { ) received } \\
\text { no intervention }\end{array}$ \\
\hline
\end{tabular}

Abbreviations: WLC, waitlist control; RCT, randomized controlled trial; BMI, body mass index; BP, blood pressure; $\mathrm{n}$, sample size after attrition; FV, fruit and vegetables; FVI, fruit and vegetable intake; PA, physical activity; FIRSSt, Food Intake Recording Software System; CIRP, Children's Intervention Rating Profile; GEMS, Girls' health Enrichment Multi-site Study.

measures, program activities, and intervention outcomes. The interventions are arranged in ascending order by year of publication.

The "Smart Bodies"45 intervention was conducted in Baton Rouge, LA, USA, among low-income minority children enrolled in urban public elementary schools, where over three quarters of students were enrolled in the National School Lunch Program. Participants completed a 12-week program delivered by teachers in the classroom. Overall, the researchers noted that the study was effective in improving knowledge of healthy nutritional practices and self-efficacy to consume fruit and vegetables; however, further research is necessary to determine the most effective age and number of tastes necessary to bring about sustained change in fruit and vegetable preferences.

The "Squire's Quest!"46 intervention was conducted in Houston, TX, USA, among low-income minority children enrolled in elementary schools, where approximately $40 \%$ of students were enrolled in the National School Lunch Program. FIRSSt (Food Intake Recording Software System), ${ }^{47}$ a computerized 24-hour dietary recall program, was utlized by students to record FVI. Overall, the researchers noted that the study was effective in increasing FVI; however, recipe goal setting seemed to be a more useful procedure for those with higher baseline consumption. More high-quality research is necessary to understand the complex relationship between goal setting and achievement for recipe preparation and dietary intake.

The "LA Sprouts"49 was a pilot study conducted among fourth and fifth grade, predominantly low-income, high-risk
Latino children in Los Angeles, CA, USA, where 94\% of the student body was eligible for free or reduced-price school meals. Preferences for vegetables, but not fruit, as well as self-efficacy to cook and consume fruit and vegetables showed increases in the treatment group post-intervention. Reductions in weight among the treatment participants were associated with increased preference for vegetables and fiber from fruit.

"Sprouting Healthy Kids"48 is a posttest only control group intervention that was conducted in Austin, TX, USA, among low-income minority children enrolled in five ethnically diverse middle schools where approximately $70 \%$ of students were enrolled in the National School Lunch Program. Overall, students who were exposed to more than two components of the program scored significantly higher on FVI, self-efficacy, and knowledge, and lower on preferences for unhealthy foods. The farmer visit component had the largest treatment effect on participants' FVI, and FVI increased by 0.352 servings for every additional component of intervention exposure.

The Memphis GEMS ${ }^{50}$ was an intervention conducted among preadolescent African-American females who were overweight or obese. The first treatment group reported increased water and vegetable consumption from baseline, and reported higher FV servings per day than the second treatment group at the 2-year follow-up visit. Physical activity measurements did not differ significantly between the two groups at either the one-year or 2-year visits. Researchers noted that interventions targeted to this population need 


\begin{tabular}{|c|c|c|}
\hline Duration/intervention activities & Evaluation measures & Intervention effects \\
\hline $\begin{array}{l}\text { 3-year program measured during } \\
\text { 2003-2004 school year, at baseline } \\
\text { I-year follow-up, and 2-year follow-up } \\
\text { - Treatment I: home visits, newsletters, } \\
\text { recipe cards, goal setting, booster phone } \\
\text { calls, goal setting } \\
\text { - Treatment 2: school playgrounds, salad } \\
\text { bars, community parks, teachers' } \\
\text { discipline and classroom practices, } \\
\text { physical education equipment, menus at } \\
\text { restaurants, posters, newsletters, frequent } \\
\text { produce buyer cards in grocery stores } \\
\text { - Treatment 3: combination of treatments } \\
\text { I and } 2 \\
\text { - Delivered by lay health educators } \\
\text { (Promotoras) }\end{array}$ & $\begin{array}{l}\text { - } \text { BMI z-score } \\
\text { - Height } \\
\text { - Weight } \\
\text { - Parental proxy-report assessed } \\
\text { parent and child PA, screen time } \\
\text { and nutrition behaviors }\end{array}$ & $\begin{array}{l}\text { - No significant intervention effects on children's BMI z-score } \\
\text { - Proportion of children classified as obese ( } \geq 95 \text { th percentile } \\
\text { weight for age) increased in all except treatment I at final } \\
\text { measurement } \\
\text { - No significant intervention effects on parent BMI or BMI } \\
\text { category } \\
\text { - Significant increase in parent-reported child physical activity, } \\
\text { reduced child frequency of watching television when getting } \\
\text { ready for school, increased child's daily consumption of FV, and } \\
\text { increased behavioral strategies for fat } \\
\text { - Parental monitoring of children's eating and activity and parent } \\
\text { support for PA significantly mediated consumption of FV, family } \\
\text { viewing of television during dinner, child PA, and less child viewing } \\
\text { television while getting ready for school }\end{array}$ \\
\hline
\end{tabular}

to begin well before puberty and should target concurrent environmental and policy changes.

The study by Somerville et $\mathrm{al}^{51}$ was a pretest-posttest intervention conducted among children aged 6-12 years who were active participants in the Boys and Girls Club gardening program in Pomona, CA, USA, and the majority were Hispanic (83\%). Participants completed a 4-month program measured at baseline and post-intervention. Overall, the average number of daily fruit and vegetable servings increased and the average number of daily chip servings decreased, showing an upward trend in fruit and vegetable snack preference. Researchers stressed the importance of the gardening curriculum used with Hispanic children and youth as a way to improve diet in this population.

"Every Day, Lots of Ways" 52 was an multicomponent intervention conducted among kindergarten and first grade African-American students attending an under-resourced urban school in the northeastern USA, where $95 \%$ of students at the school received free breakfast and lunch. An increase in nutrition knowledge was found in the treatment group, with no differences between knowledge scores for the treatment group at posttest and one-month follow up. There were no significant changes in vegetable consumption among the treatment group from preintervention to post-intervention, and the post-intervention rates were similar to those of the waitlist control. Mean daily vegetable intake for experimental group was 3.21, mean daily intake for waitlist control group was 3.27 servings per day. Researchers noted that the limitations of this study could be directly correlated with variable findings and this type of intervention should be explored further for more accurate measures of effectiveness.

"Students and Parents Actively Involved in Being Fit"53 was a one-group pretest-posttest intervention conducted in the USA among African-American students aged 10-12 years and their parents/guardians (average age 40.6 years). There were significant decreases in body mass index (BMI) $z$-score, body fat percentage, resting diastolic blood pressure, and walk/run time in parents/guardians, as well as significant decreases in resting systolic and diastolic blood pressure in children. There was also an increase in fruit consumption in both parents/guardians and children and improvements in fruit juice, salad, and nonfried potato consumption in children. Researchers noted that children gained more diet-related benefits while parents/guardians gained more fitness-related benefits; however, the intervention was effective at changing short-term behaviors.

"Go Girls" $" 54$ was a randomized controlled trial conducted among adolescent African-American females from ten predominantly middle socioeconomic status churches in the USA, where participants were $12-15$ years of age with a BMI $z$-score above the 90 th percentile for age and sex. Parents were invited to attend every other session. There was no significant difference in BMI $z$-score at the 6-month follow-up in the treatment group that received the high-intensity individual/ family level intervention. Females in treatment group who attended more than three quarters of the sessions had significantly lower BMI $z$-score, weight, waist and hip circumference, and body fat percentage compared with females in the 
same group who attended fewer sessions. Researchers noted the benefits among high attenders, despite null results.

"One Body, One Life" ${ }^{55}$ was a one-group pretest-posttest intervention conducted among children 7-16 years of age and adults from local schools and community groups in Coventry, UK, where one or more members of the family were underweight, overweight, or obese. Families were ethnically diverse and from deprived areas in Coventry. There was a significant reduction in the amount of chips, crisps, sweets, and fizzy drinks consumed per day for children; there was also a reduction in fast food consumption (significant for parents, but not for children). Significant changes in knowledge, physical activity, and fruit and vegetable portions consumed daily were found for both children and adults. Overall, the number of participants consuming five or more fruit and vegetable portions a day increased from $21 \%$ to $33 \%$.

"Aventuras Paras Niños" ${ }^{56}$ was a randomized controlled trial conducted among Latino parents and their children (ages kindergarten through second grade) in San Diego, CA, USA, with families who had no major health problems and lived within school attendance boundaries. There were no significant effects on children's BMI $z$-scores; in fact, the proportion of children classified as obese increased in all at the final measurement except in the treatment group that received the high-intensity individual/family level intervention. There were no significant effects on parent BMI or BMI category. There was a significant increase in parent-reported child physical activity, reduced child frequency of watching television when getting ready for school, increased child's daily consumption of fruit and vegetables, and increased behavioral strategies that a parent uses to decrease dietary fat intake. Researchers noted that parental monitoring of children's eating and activity significantly mediated healthy behaviors.

\section{Discussion}

The purpose of this investigation was to systematically review interventions conducted between 2003 and 2013 that targeted increased FVI in minority children in the context of community and school environments. Of the eleven interventions evaluated, one was conducted in the UK and ten were implemented in the USA. With obesity being an epidemic of tremendous proportions among children and adults around the world and the limited number of interventions conducted over the past decade, it would be highly advantageous to design and evaluate interventions similar to those mentioned in this article in other countries.
Based on the increase in minority populations in the USA, along with the overwhelming prevalence of obesity, it is natural that the majority of the studies conducted recently would arise from the USA; however, the global burden of these issues necessitates more interventions that target minority populations in the school and community environments around the world. Conducting a greater number of interventions in areas outside the USA would provide insight into effective future program implementation around the world.

While both the school and community-based interventions utilized over the past decade have individually shown significant impacts on changing dietary behaviors in children, the results of this review reveal that community members and organizations can serve as supplementary approaches and partner with schools to design even more successful interventions based on these combined resources. Multicomponent school-based interventions have had a great deal of success in impacting self-efficacy levels as well as actual eating behaviors in children through classroom and cafeteria components, while multicomponent communitybased interventions have noted significant effects from utilizing hands-on gardening programs and environmental and policy changes. However, both the school and community-based interventions reviewed noted the lack of resources (space, time, financial, and personnel) as a limitation, specifically with multicomponent interventions. Therefore, combining these resources by creating multicomponent school-based programs that include community components, such as farmers market visits, master gardener classes, and concurrent environmental and policy changes, has the potential to help generate more high-quality studies from which to draw evidence-based conclusions regarding the most effective means of impacting health behaviors among minority children in the school and community settings.

\section{Intervention design}

\section{Strengths}

Multimedia formatted games, ${ }^{44,46}$ as well as numerous types of hands-on activities, ${ }^{44,49-51,53-56}$ were utilized to promote increased asking behavior, food preparation, produce shopping, fast food selection, problem solving, goal setting, self-regulation, and self-reward skills in relation to FVI. These interactive sessions also measured fruit and vegetable preference and self-efficacy for FVI. Four of the interventions $44,48,51,55$ attempted to increase knowledge by including educational activities and lessons, and were designed with a specific 
curriculum tailored toward increasing FVI or preferences for fruit and vegetables. Several interventions had a garden-based design ${ }^{49}$ or included a farm component, ${ }^{48-51}$ and encouraged increased preference based on involvement in the process of growing foods and developing preferences for foods from the garden. Researchers from one study ${ }^{49}$ noted the feasibility of a cooking, nutrition, and afterschool gardening program in a garden-based setting, and suggested that such an intervention may be effective in influencing attitudes, perceptions, and preferences for fruit and vegetables. However, because this type of intervention has not been frequently implemented, additional evaluations of similar interventions are necessary to further understand the efficacy of garden-based interventions with regard to increasing FVI in minority children.

Approximately two thirds of the interventions $(n=7)$ targeted children as the sole agent of change, ${ }^{44,46,49-52}$ while the remaining interventions included parents in the intervention process $(n=4)$ to varying degrees. Parental involvement in weight loss interventions has been effective with younger children in previous studies, and could translate to interventions focusing on dietary behaviors. ${ }^{52}$

All of the examined studies utilized a quantitative design, with six employing a randomized controlled trial design. ${ }^{44,46,48,52,54,56}$ While each type of design has both strengths and weaknesses, randomized controlled trials are the most rigorous and offer the strongest control against threats to both external and internal validity.

\section{Limitations}

Of the studies that did not employ a randomized controlled trial design $(n=5)$, one employed a posttest-only design, ${ }^{50}$ three employed pretest-posttest design, ${ }^{51,53,55}$ and one employed a quasi-experimental design. ${ }^{49}$ Four of the interventions did not incorporate a control group, which limits the ability to rule out confounding variables. ${ }^{51,53-55}$

While the randomized controlled trial design offers the most rigor of all the designs, they are not always possible to conduct due to limited resources. Quasi-experimental interventions are often used when randomized controlled trials are not possible; however, they lack randomization and create a substantial threat to internal validity.

One of the examined studies included formative research focus groups to help determine themes and develop culturally appropriate messages. ${ }^{54}$ However, no other cultural tailoring was reported in the remainder of the studies, which serves as a significant limitation. One study $^{56}$ reported using Health Belief Model, ${ }^{57}$ but did not explain specifically how the model was used in program development. Cultural tailoring, defined by Pasick et $a 1^{58}$ as "the development of interventions, strategies, messages and materials to conform with specific cultural characteristics", is critical to the success of programming in diverse populations. Long-term lifestyle behavior change may be achievable if populations are provided with culturally appropriate programs that have a sense of local ownership. ${ }^{59}$ Health messages and intervention strategies should be tailored based on baseline child weight categories, minority status, and age, amidst other factors. ${ }^{56}$

While several interventions targeted parents along with children, parent involvement was not easily ascertained due to work schedules and a number of other factors. ${ }^{53-56}$ To determine the effectiveness of parental involvement in interventions such as these, parental involvement should be consistent and purposeful. Also, while the focus on Latino or African-American populations provides further insight into developing appropriately tailored messages for these populations, it limits the generalizability of the results unless the study can demonstrate external validity. Most of the studies did not have a physical activity component, making it impossible to examine the concurrent effects of increased physical activity on dietary behavior change. ${ }^{44,46,49-52}$

\section{Intervention implementation}

\section{Strengths}

Theory-based interventions offer many advantages over interventions that do not employ a specific theory, such as reduced intervention dosage, increased likelihood of behavior change, and efficient allocation of resources. ${ }^{60}$ Interventions based on theory can help understand existing behavior and guide the design implementation so that interventions are accurately targeted. Of the eight studies that utilized social cognitive theory for intervention design and implementation, six reported operationalizing constructs included in this theory, the majority focusing on self-efficacy for making healthy food choices. ${ }^{44,46,48,49,54,56}$ Application of theory-based interventions, specifically social cognitive theory, in the design and implementation of fruit and vegetable interventions can substantially enhance this effort to create healthy behavior change by providing a consistent framework. ${ }^{61}$

The multicomponent nature of the implementation of these programs inherently recognizes the necessity of approaching behavior change from multiple perspectives, realizing the complexity of individuals and that focusing on a singular component may not change behavior. The duration of the interventions ranged from 5 weeks to 3 years, with the 
majority being approximately 10-12 weeks long. Goal selection/setting for recipe preparation was used in several of the studies, where each participant was guided to select a fruit and vegetable recipe from a list and was then able to prepare that recipe through the use of a online computer program, in an on-site kitchen or at home. ${ }^{46,50,55,56}$

One study realized the benefit of creating an environment of "inclusivity" during the implementation process, even noting that this type of atmosphere has the potential to reduce negative attitudes towards overweight/obese people by encouraging them to work together towards a common goal and could also provide numerous benefits at a societal level. ${ }^{55}$ This concept of inclusivity could be affected by culture, which is defined as a system of shared understanding that shapes and, in turn, is shaped by experience. Culture is a learned concept, and among minority populations, is distributed within a group in that not everyone possesses the same knowledge, attitudes, practices, or interpretable methods of communication. Among these groups, there are a host of differences pertaining to obesity, such as understanding of its cause, course, and cure, the extent to which it is perceived as illness, perception of attractive versus unattractive physical appearance, and perception and valuation of a healthpromoting diet. Many cultures even have dramatic variations in traditional diets, with globalization being associated with fewer home-cooked meals, more calories consumed in restaurants, increased snacking between meals, and increased availability of fast foods in schools.

Community engagement in the majority of the studies showed the potential effectiveness of involving communities in changing dietary behaviors in children. ${ }^{49,50,51,53-56}$ Involving the community when attempting to change behavior continues to substantiate this notion that behavior change does not occur in one single domain, but must be taken into account by viewing the individual as a whole, ie, as part of a family, social network, and community.

\section{Limitations}

Because making healthy food choices is a lifelong process, it is necessary to develop more interventions that include longterm evaluation of food preferences and choices associated with these preferences in an attempt to reduce the risk of obesity and other associated diseases.

While goal setting is a procedure that is frequently used to change behavior, there is little evidence relating goal setting to dietary behaviors in children, such as setting goals to prepare recipes. ${ }^{61}$ Also, home availability in low-income homes for all types of vegetables was not taken into account.
Lastly, goal setting was verified by parental confirmation, which could limit the validity of the results. This could also suggest that goal setting may be an even stronger predictor of change if goal achievement data were more valid.

Resources were a limitation in several of the studies. While many of the interventions used classrooms, the limited capabilities of site kitchens as well as the availability of other concurrent activities for children posed a threat to the fidelity of implementation in one study. ${ }^{51}$ There could be potential difficulties with attempting to incorporate recipe preparation activities into an intervention without access to a kitchen. Also, the number of staff necessary to implement the intervention served as a significant limitation in one study, resulting in higher staffing costs than originally figured and a longer implementation time required. ${ }^{54}$

In another study, recruitment of students and parents was an unplanned challenge, creating the potential for selection bias. ${ }^{48}$ In one study that specifically focused on reducing BMI $z$-scores, program staff noted that implementation should focus on parallel environmental and policy changes to improve the contexts for dietary behavior change. ${ }^{50}$ Examining multiple levels of influence on behavior has the potential to provide more effective programming by targeting taste preferences and habits, nutritional knowledge and skills, patterns within peer groups, friends and family, and environmental factors that affect food access and availability. Ecological frameworks are gaining momentum among researchers because they provide a means of approaching parallel contexts to effect behavior change. Studies have shown $^{63}$ that increasing FVI among minority populations is the interplay of personal, cultural, and environmental factors that can be described using the socioecological model. ${ }^{64}$ Employing an ecological framework would be beneficial for researchers attempting to incorporate both the school and the community as components of a larger-scale intervention as it would help provide a more thorough understanding of the multiple factors and barriers that impact dietary behaviors and could also help to provide guidance for developing culturally appropriate intervention strategies. ${ }^{64}$

\section{Intervention evaluation}

\section{Strengths}

Students completed dietary assessments in six studies, some using a validated food recording system, some measuring intake through parental proxy reporting in a food frequency questionnaire, and the rest using child self-report. ${ }^{46,48,51,53,55,56}$ Seven of the studies had sample sizes between 100 and 1,600 , which can provide a more representative sample and 
limit the influence of outliers as well as produce results among variables that are significant. ${ }^{44,46,48,50,54-56}$

Data were collected at baseline in ten of the eleven studies; however, posttest evaluation procedures and time intervals differed. Two of the post-intervention evaluations were conducted at 2-year follow up, ${ }^{50,56}$ one evaluation was conducted at one-year follow-up, ${ }^{54}$ and in the rest ${ }^{44.46,48,51,53,55}$ immediately following the intervention $(n=6)$, one week $\operatorname{afterwards}^{49}(\mathrm{n}=1)$, and one month $\operatorname{later}^{52}(\mathrm{n}=1)$. One specific study performed process evaluation to ensure classroom implementation integrity, lunchtime implementation integrity, teacher and classroom assistant satisfaction, and student satisfaction. ${ }^{52}$ This type of evaluation helps to ensure program fidelity.

Objective measures such as BMI $z$-score were measured in multiple studies, as well as blood pressure, total body water, visceral fat, and hip and waist circumference. ${ }^{49,50,51,53,54}$ Objective measures often provide a more accurate view of behavior and are beneficial to examine along with subjective measures such as knowledge, preferences for foods, and self-efficacy.

\section{Limitations}

A significant limitation as noted by the researchers was that the majority of the assessments were based on participant recall, which is subject to bias as a result of human error and minimizes the likelihood of detecting a relationship. ${ }^{44,46,48,49,51,53}$ While the majority of sample sizes were large, the small sample sizes in several studies limit the validity of the results. ${ }^{49,51,52,53}$ While recipe goal setting was significant in increasing FVI, recipe goal achievement at home was verified by parents, again limiting the validity of the results. ${ }^{46}$ Although students completed multiple days of dietary assessment using a validated computerized program, ie, FIRSSt (Food Intake Recording Software System), ${ }^{47}$ responses were based on participant recall, which could include bias as a result of human error. Other than the one study mentioned earlier, evaluation was not discussed in any of the remaining ten studies. Process evaluation refers to measuring if the program is delivered as intended, and is an important part of any intervention because it can help determine program fidelity. Programs with high fidelity can rule out poorly implemented program components as a reason for any nonsignificant findings. Failure to evaluate program fidelity makes it difficult to confirm if nonsignificant program outcomes were due to ineffective intervention components or inadequate delivery of the intervention curriculum. Future intervention studies should use process evaluation in order to help determine efficacy of program components.

Self-report measures can be helpful in understanding behaviors; however, they can provide inaccurate results based on human error. Seven of the included studies ${ }^{49,50,51,53-56}$ assessed anthropometric measurements along with behavioral measurements, while four of the studies ${ }^{44,46,48,52}$ assessed behavioral measurements only, and three of these $\mathrm{e}^{44,46,48}$ based these behavioral measurements solely on participant self-report. One study ${ }^{56}$ applied parental-proxy report of behaviors for self and child. To determine the objective efficacy of interventions, anthropometric measurements, such as BMI $z$-score, should be assessed along with behavioral self-report.

\section{Practical implications and recommendations for enhancing community and school-based interventions}

Interventions aimed at increasing FVI among minority children should not only incorporate education, but also focus on changing preferences by involving children in concrete experiences of food. For example, food preparation, tasting activities, agricultural education, and school gardens should be used to help children develop a personal connection with their food and an enduring relationship with healthy food choices, ${ }^{56,64,65}$ which is where the community-school partnership could potentially be extremely effective, providing resources for education in the schools and hands-on experience in the community. Based on the multicomponent nature of these studies, future research should focus on determining the effectiveness of specific components to help guide intervention design. Viewing parents as agents of change in the family and incorporating them to a greater extent in the interventions could potentially result in more significant outcomes. Interventions incorporating these objectives should prioritize evaluation. Parents could record dietary as well as physical activity behaviors as proxy for their children; however, more objective measurement tools, such as accelerometers, pedometers, and anthropometric measures, should also supplement these records.

Although multicomponent school-based interventions can be effective in changing the behavior of children, they can also require more resources than are accessible, both financial and personnel-related. Given the current economic climate, costs of program delivery have become substantial limitations in many schools and communities. While some health 
education programs such as "Smart Bodies" are designed to use existing resources, many programs such as "Go Girls" end up requiring more resources than are available. In this study, the intervention required a larger number of staff than initially expected, which resulted in higher than anticipated staffing costs, extension of program delivery time, and scheduling complexities. However, by pooling resources, community members and organizations can serve as supplementary resources to partner with schools and design more successful interventions with reduced costs and increased access to these resources. Interventions with greater cost-effectiveness have the potential for increased sustainability over a longer period of time. These potential community-based resources and partnerships should be explored when designing future evaluations. Also, research has shown that family-based treatment may be more cost-effective for families with overweight/obese children and parents as opposed to treating the parent and child separately. ${ }^{66}$ Given the impact that parents have on the dietary behaviors of their children, these research findings should be considered when designing health education interventions, and should target both parent and child simultaneously.

Today's children aged 8-18 years consume multiple types of media and spend more time (approximately 44.5 hours per week) in front of computers, televisions, and game screens than any other activity in their lives except sleeping. ${ }^{67}$ A great deal of research has found multiple associations between increases in advertising of non-nutritious foods and rates of childhood obesity. ${ }^{67}$ With the rise in consumption of fast food in developed and developing nations, and the existing knowledge that fast food typically incorporates many potentially adverse dietary factors that contribute to obesity in children, ${ }^{68}$ the authors believe that multicomponent interventions would benefit by including a component geared towards affecting the marketing of fast food to children. An example of this is the "Aventura Para Niños" study, ${ }^{56}$ which was developed based on a socioecological framework designed to promote health in Latino communities and included an environmental component that specifically targeted local fast food restaurants. However, as noted in this study, making environmental changes is challenging and complicated, necessitating the involvement of community members, leaders, and stakeholders. Access to increased resources through school and community collaboration could generate a greater ability to effect change at this environmental level. Also, at the interpersonal level, while the correlation between dietary behaviors and peer influence is still somewhat unclear, the authors believe that including a peer influence component to help understand this relationship better could help strengthen multicomponent interventions.

While social cognitive theory has often been used successfully in changing dietary behaviors, such as increased FVI, it would be beneficial to examine this behavior on multiple levels to include the influences of the family, community, and environment by combining social cognitive theory with an ecological approach. In studies targeting FVI among minority groups, those that used the socioecological model were more culturally appropriate and sensitive to the characteristics and realities of the target population based on their capacity to examine personal, cultural, and environmental factors. ${ }^{68,69}$ Based on the knowledge that theory-based interventions can generate significant outcomes, it is imperative that researchers operationalize constructs from the theory on which their intervention is founded to determine the effectiveness of the theory and correlation with specific behavior changes. This process can help to determine which theoretical constructs work and to what extent more effective intervention designs can be developed.

\section{Disclosure}

The authors report no potential conflicts of interest in this work. The authors received no financial support for the research, authorship, and/or publication of this paper.

\section{References}

1. Craig R, Mindell J, Hirani V. Healthy Survey for England 2008: Physical activity and fitness. Available from: http://www.hscic.gov.uk/pubs/ hse08physicalactivity. Accessed June 8, 2014.

2. Ogden CL, Carroll MD, Curtin LR, McDowell MA, Tabak CJ, Flegal KM. Prevalence of overweight and obesity in the United States, 1999-2004. JAMA. 2006;295:1549-1555.

3. Troiano RP, Flegal KM, Kuczmarski RJ, Campbell SM, Johnson CL. Overweight prevalence and trends for children and adolescents: the National Health and Nutrition Examination Surveys, 1963 to 1991. Arch Pediatr Adolesc Med. 1995;149:1085-1091.

4. Ogden CL, Carroll MD, Curtin LR, Lamb MM, Flegal KM. Prevalence of high body mass index in US children and adolescents, 2007-2008. JAMA. 2010;303:242-249.

5. Freedman DS, Khan LK, Serdula MK, Ogden CL, Dietz WH. Racial and ethnic differences in secular trends for childhood BMI, weight, and height. Obesity (Silver Spring). 2006;14:301-308.

6. Centers for Disease Control and Prevention, National Center for Health Statistics. NHANES 2009-2010. Available from: http://wwwn.cdc.gov/ nchs/nhanes/search/nhanes09_10.aspx. Accessed November 15, 2013.

7. Cullen KW, Watson K, Himes JH, et al. Evaluation of quality control procedures for 24-h dietary recalls: results from the Girls Health Enrichment Multi-Site Studies. Prev Med. 2004;38 Suppl:S14-S23.

8. Treuth MS, Sherwood NE, Butte NF, et al. Validity and reliability of activity measures in African-American girls for GEMS. Med Sci Sports Exerc. 2003;35:532-539.

9. Treuth MS, Sherwood NE, Baranowski T, et al. Physical activity self report and accelerometry measures from the Girls health Enrichment Multi-site Studies. Prev Med. 2004;38:S43-S49.

10. Strauss RS, Pollack HA. Epidemic increase in childhood overweight, 1986-1998. JAMA. 2001;286:2845-2848. 
11. Wang Y, Lobstein T. Worldwide trends in childhood overweight and obesity. Int J Pediatr Obes. 2006;1:11-25.

12. Bazzano LA. The high cost of not consuming fruits and vegetables. J Am Diet Assoc. 2006;106;1364-1368.

13. Williams CL. Nutrition intervention and health risk reduction in childhood: creating healthy adults. Pediatrician. 1985;12:97-101.

14. McMurray RG, Harrell JS, Bangdiwala SI, Bradley CB, Deng S, Levine A. A school-based intervention can reduce body fat and blood pressure in young adolescents. J Adolesc Health. 2002;31:125-132.

15. United States Department of Health and Human Services. Healthy People 2020. Available from: http://www.healthypeople.gov/2020/ default.aspx. Accessed November 6, 2013.

16. Lakkakula AP, Zanovec M, Silverman L, Murphy E, Tuuri G. Black children with high preferences for fruits and vegetables are at less risk of being at risk of overweight or overweight. J Am Diet Assoc. 2008;108: 1912-1915.

17. Hung HC, Joshipura KJ, Jiang R, et al. Fruit and vegetable intake and risk of major chronic disease. $J$ Natl Cancer Inst. 2004;96: 1577-1584.

18. Koplan JP, Liverman CT, Kraak VI. Preventing childhood obesity: health in the balance: executive summary. $J$ Am Diet Assoc. 2005;105:131-138.

19. Mendoza JA, Drewnowski A, Cheadle A, Christakis DA. Dietary energy density is associated with selected predictors of obesity in US children. J Nutr. 2006;136:1318-1322.

20. Prentice AM, Jebb SA. Fast foods, energy density, and obesity: a possible mechanistic link. Obes Rev. 2003;4:187-194.

21. World Health Organization. Diet, nutrition, and the prevention of chronic diseases. World Health Organization Technical Report Series 916. Geneva, Switzerland: World Health Organization; 2003. Available from: http:// whqlibdoc.who.int/trs/who_trs_916.pdf. Accessed June 6, 2014.

22. Bowman SA, Gortmaker SL, Ebbeling CB, Pereira MA, Ludwig DS. Effects of fast-food consumption on energy intake and diet quality among children in a national household survey. Pediatrics. 2004;113:112-118.

23. Casagrande SS, Wang Y, Anderson C, Gary TL. Have Americans increased their fruit and vegetable intake? The trends between 1988 and 2002. Am J Prev Med. 2007;32:257-263.

24. Guenther P, Dodd KW, Reedy J, Krebs-Smith SM. Most Americans eat much less than recommended amounts of fruits and vegetables. JAm Diet Assoc. 2006;106:1371-1379.

25. Dave JM, Evans AE, Saunders RP, Watkins KW, Pfeiffer KA. Associations among food insecurity, acculturation, demographic factors, and fruit and vegetable intake at home in Hispanic children. J Am Diet Assoc. 2009;109:697-701.

26. Centers for Disease Control and Prevention, National Center for Health Statistics. NHANES 2001-2002. Available from: http://wwwn.cdc.gov/ nchs/nhanes/search/nhanes01_02.aspx. Accessed November 15, 2013.

27. Robinson-O'Brien R, Story M, Heim S. Impact of garden-based youth nutrition intervention programs: a review. $J$ Am Diet Assoc. 2009;109:273-280.

28. Singh AS, Mulder C, Twist JW, van Mechelen W, Chinapaw MJ. Tracking of childhood overweight into adulthood: a systematic review of literature. Obes Rev. 2008;9:474-488.

29. Finkelstein EA, Strombotne KL. The economics of obesity. Am J Clin Nutr. 2010;91:S1520-S1524.

30. Drewnowski A, Spector SE. Poverty and obesity: the role of energy density and energy costs. Am J Clin Nutr. 2004;79:6-16.

31. Baxter SD, Thompson WO. Fourth grade children's consumption of fruit and vegetable items available as part of school lunches is closely related to preference. J Nutr Educ Behav. 2002;34:166-171.

32. Desor JA, Maller O, Andrews K. Ingestive responses of human newborns to salty, sour, and bitter stimuli. J Comp Physiol Psychol. 1975;89:966-970.

33. Desor JA, Maller O, Greene LS. Preference for sweet in humans: infants, children and adults. In: Weiffenbach JM, editor. Taste and Development: The Genesis of Sweet Preference. Washington, DC, USA: US Government Printing Office; 1977.
34. Nisbett RE, Gurwitz SB. Weight, sex, and the eating behavior of human newborns. J Comp Physiol Psychol. 1977;73:245-253.

35. Pelchat ML, Pliner P. "Try it you'll like it." Effects of information on willingness to try novel foods. Appetite. 1995;24:153-165.

36. Skinner JD, Carruth BR, Wendy B, Ziegler PJ. Children's food preferences: a longitudinal analysis. J Am Diet Assoc. 2002;102: $1638-1647$.

37. Mullen MC, Shield J. Childhood and Adolescent Overweight: The Health Professionals Guide to Identification, Treatment and Prevention. Chicago, IL, USA: American Dietetic Association; 2004.

38. Weinstein E, Rosen E. Teaching Children About Health: A Multidisciplinary Approach. 2nd ed. Belmont, CA, USA: Wadsworth/ Thomson Learning; 2003.

39. Burchett $\mathrm{H}$. Increasing fruit and vegetable consumption among British primary schoolchildren: a review. Health Educ. 2003;103:99-109.

40. Levine E, Olander C, Lefebvre C, Cusick P, Biesiadecki L, McGoldrick D. The team nutrition program pilot study: lessons learned from implementing a comprehensive school-based intervention. J Nutr Educ Behav. 2002;34:109-116.

41. Newell SA, Huddy AD, Adams JK, Miller M, Holden L, Dietrich UC. The tooty fruity veggie project: changing knowledge and attitudes about fruit and vegetables. Aust N Z J Public Health. 2004;28:288-295.

42. Wang Y, Tussing L, Odoms-Young A, et al. Obesity prevention in low socioeconomic status urban African-American adolescents: study design and preliminary findings of the HEALTH-KIDS study. Eur J Clin Nutr. 2006;60:92-103.

43. Dowrick PW, Power TJ, Manz PH, Ginsburg-Block M, Leff SS, Kim-Rupnow S. Community responsiveness: examples from underresourced urban schools. J Prev Interv Community. 2001;21: 71-90.

44. Tuuri G, Zanovec M, Silverman L, et al. "Smart Bodies" school wellness program increased children's knowledge of healthy nutrition practices and self-efficacy to consume fruit and vegetables. Appetite. 2009;52:445-451.

45. Bandura A. Health promotion by social cognitive means. Health Educ Behav. 2004;31:143-164.

46. Cullen KW, Watson KB, Zakeri I, Baranowski T, Baranowski JH. Achieving fruit, juice, and vegetable recipe preparation goals influences consumption by 4 th grade students. Int J Behav Nutr Phys Activ. 2007;4:28.

47. Baranowski T, Baranowski J, Cullen KW. The Food Intake Recording Software System (FIRSSt): validation against 24-hour dietary recalls. J Am Diet Assoc. 2002;102:380-385.

48. Gatto NM, Ventura EE, Cook LT, Gyllenhammer LE, Davis JN. LA Sprouts: a garden-based nutrition intervention pilot program influences motivation and preference for fruits and vegetables in Latino youth. J Acad Nutr Diet. 2012;112:913-920.

49. Evans A, Ranjit N, Rutledge R, et al. Multiple components of a garden-based intervention for middle school students increases fruit and vegetable consumption. Health Promot Pract. 2012;13: 608-616.

50. Klesges RC, Obarzanek E, Kumanyika S, et al. The Memphis Girls' health Enrichment Multi-site Studies (GEMS): an evaluation of the efficacy of a 2-year obesity prevention program in African-American girls. Arch Pediatr Adolesc Med. 2010;164:1007-1014.

51. Somerville M, Kessler LA, Wallace SP, Burns-Whitmore B. The effect of a garden-based nutrition education program on the consumption of fruits and vegetables by Hispanic children. Calif J Health Promot. 2012;10:20-25.

52. Blom-Hoffman J, Kelleher C, Power TJ, Leff SS. Promoting healthy food consumption among young children: evaluation of a multi-component nutrition education program. J School Psychol. 2004;42:45-60.

53. Engels HJ, Gretebeck RJ, Gretebeck KA, Jimenez L. Promoting healthful diets and exercise: efficacy of a 12-week after-school program in urban African Americans. J Am Diet Assoc. 2005;105:455-459.

54. Resnicow K, Taylor R, Baskin M, McCarty F. Results of Go Girls: A weight control program for overweight African-American adolescent females. Obes Res. 2005;13:1739-1748. 
55. Towey M, Harrell R, Lee B. Evaluation of "One Body, One Life": A community-based family intervention for the prevention of obesity in children. Available from: http://www.hindawi.com/journals/ jobe/2011/619643/. Accessed June 6, 2014.

56. Crespo N, Elder JP, Ayala CX, et al. Results of a multi-level intervention to prevent and control childhood obesity among Latino children: the Aventuras Para Niños Study. Ann Behav Med. 2012;43:84-100.

57. Rosenstock I. Historical origins of the health belief model. Health Educ Behav. 1974;2:328-335.

58. Pasick RJ, D’Onofrio CN, Otero-Sabogal R. Similarities and differences across cultures: questions to inform a third generation for health promotion research. Health Educ Q. 1996;23:S142-S161.

59. Jenum AK, Lorentzen CA, Ommundsen Y. Targeting physical activity in a low socioeconomic status population: observations from the Norwegian 'Romsas in Motion' study. Br J Sports Med. 2009;43:64-69.

60. Sharma M, Romas JA. Theoretical Foundations of Health Education And Health Promotion. Sudbury, MA, USA: Jones and Bartlett; 2008.

61. World Health Organization. Fruit and vegetable promotion initiative. Report of Geneva, August 25-27, 2003. Geneva, Switzerland: World Health Organization; 2003. Available from: http://www.who.int/ dietphysicalactivity/publications/f\&v_promotion_initiative_report.pdf. Accessed June 6, 2014.
62. Robinson T. Applying the socio-ecological model to improving fruit and vegetable intake among low-income African Americans. J Commun Health. 2008;33:395-406.

63. Bronfenbrenner U. Toward an experimental ecology of human development. Am Psychol. 1977;32:513.

64. Contento I. Children's thinking about food and eating - a Piagetian-based study. J Nutr Educ Behav. 1981;13:S86-S90.

65. Birch LL. Development of food preferences. Annu Rev Nutr. 1999;19: 41-62.

66. Epstein L, Paluch R, Wrotniak B, et al. Cost-effectiveness of family-based group treatment for child and parental obesity. Child Obes. 2014;10:114-121.

67. Ebbeling C, Pawlak D, Ludwig D. Childhood obesity: public-health crisis, common sense cure. Lancet. 2002;360:473-482.

68. Befort C, Kaur H, Nollen N, et al. Fruit, vegetable, and fat intake among non-Hispanic Black and non-Hispanic white adolescents: associations with home availability and food consumption settings. J Am Diet Assoc. 2006;106:367-373.

69. James D. Factors influencing food choices, dietary intake, and nutrition-related attitudes among African Americans: application of a culturally sensitive model. Ethn Health. 2004;9:349-367.

\section{Publish your work in this journal}

Pediatric Health, Medicine and Therapeutics is an international, peerreviewed, open access journal publishing original research, reports, editorials, reviews and commentaries. All aspects of health maintenance, preventative measures and disease treatment interventions are addressed within the journal. Practitioners from all disciplines are invited to submit

\section{Dovepress}

their work as well as healthcare researchers and patient support groups. The manuscript management system is completely online and includes a very quick and fair peer-review system. Visit http://www.dovepress.com/ testimonials.php to read real quotes from published authors. 